\title{
Een rookvrije zone in Rotterdam: wat is er te winnen?
}

\author{
Nazmi Dereci · Leonieke J. Breunis · Marlou L. A. de Kroon · Jasper V. Been
}

Published online: 3 February 2020

(c) The Author(s) 2020

Samenvatting Het doel van dit onderzoek was het rookgedrag meten binnen de voorgenomen eerste rookvrije zone in Rotterdam. In de winter van 2018-2019 is gedurende 37 dagen het aantal rokers geteld op het voorgenomen rookvrije terrein rondom het Erasmus MC, de nabijgelegen Hogeschool Rotterdam en het Erasmiaans Gymnasium. Ook het gebruik van de rookabri, kenmerken van de rokers en het aanspreekgedrag zijn geobserveerd. Op basis van deze metingen schatten wij dat er tijdens werktijden dagelijks bijna 4.500 rokers waren in de voorgenomen rookvrije zone. De meeste rokers bevonden zich rondom de hoofdingang van het Erasmus MC $(n=948)$ en de ingang van de Hogeschool $(n=614)$. Van de rokers rondom het Erasmus MC was 30\% herkenbaar als Erasmus MC-werknemer en $4 \%$ als patiënt. Rondom de scholen was $69 \%$ herkenbaar als student en $12 \%$ als werknemer. Rondom het Erasmus MC maakte $75 \%$ van de rokers geen gebruik van een rookabri. Van hen werd slechts $0,2 \%$ zichtbaar

Electronic supplementary material The online version of this article (https://doi.org/10.1007/s12508-020-00251-1) contains supplementary material, which is available to authorized users.

\section{N. Dereci · dr. J. V. Been $(\triangle)$}

Divisie Neonatologie, Afdeling Kindergeneeskunde, Erasmus MC - Sophia Kinderziekenhuis, Universitair Medisch Centrum Rotterdam, Rotterdam, Nederland

j.been@erasmusmc.nl

N. Dereci · L. J. Breunis · dr. M. L. A. de Kroon · dr. J. V. Been Afdeling Verloskunde en Gynaecologie, Erasmus MC Sophia Kinderziekenhuis, Universitair Medisch Centrum Rotterdam, Rotterdam, Nederland

\section{dr. J. V. Been}

Afdeling Maatschappelijke Gezondheidszorg, Erasmus MC, Universitair Medisch Centrum Rotterdam, Rotterdam, Nederland verzocht om elders te roken. Rondom de onderwijsinstellingen rookte $25 \%$ binnen de bestaande rookvrije zone voor een van de ingangen. Van hen werd 5\% zichtbaar verzocht om elders te roken. Dagelijks zijn er veel rokers in het voorgenomen rookvrije gebied in Rotterdam. Het gebruik van de rookabri's en het aanspreekgedrag was minimaal. De uitkomsten van dit onderzoek laten zien welke potentiële winst er te behalen is bij het implementeren van een volledig rookvrij beleid.

Trefwoorden rookvrije zone $\cdot$ ziekenhuis · onderwijsinstellingen · observationeel veldonderzoek $\cdot$ nakoming

\section{A smoke-free zone in Rotterdam: quantifying the room for improvement}

Abstract We aimed to assess smoking patterns within the planned first inner-city smoke-free zone in Rotterdam, Netherlands. During 37 days in winter $2018 / 2019$ we systematically counted people who smoked in the planned smoke-free zone encompassing the Erasmus MC (EMC), the Rotterdam University of Applied Sciences (RUAS), and the Erasmiaans high school (EHS). The daily number of smokers was estimated for each location. We recorded smokers' characteristics, their compliance with the current policy, and whether non-compliant smokers were addressed. On average, there were almost 4,500 smokers within the planned smoke-free zone every weekday during regular working hours. The largest numbers of smokers were observed nearby the EMC main entrance $(n=948)$ and the main entrance of the RUAS $(n=614)$. Of smokers near the EMC, $30 \%$ were identified as EMC employees and $5 \%$ as patients. Near the EHS/RUAS, $69 \%$ of smokers were identified as students and $12 \%$ as employees. Near the EMC $75 \%$ 
of smokers smoked outside of a location where smoking was permitted. Only $0.2 \%$ of these smokers were addressed and asked to smoke elsewhere. Near the EHS/RUAS $25 \%$ of smokers smoked outside of a location where smoking was permitted. Only 5\% of these smokers were addressed and asked to smoke elsewhere. This study shows there is potentially a lot to gain by implementing a smoke-free zone.

Keywords Smoke-free zone · Hospital · Schools • Observational study · Compliance

\section{Een rookvrije zone in Rotterdam}

Roken is de belangrijkste voorkombare risicofactor voor ziekte en vroegtijdige sterfte wereldwijd [1]. Jaarlijks overlijden naar schatting 20.000 Nederlanders aan de gevolgen van roken [2]. De laatste jaren lijkt een sociale normverschuiving gaande rondom roken. Ook de politiek neemt nadrukkelijker haar verantwoordelijkheid om de negatieve gevolgen van roken aan te pakken. De totstandkoming van het Nationale Preventieakkoord is daarvan een goed voorbeeld [3]. Om te komen tot een rookvrije generatie ontstaan daarnaast steeds meer initiatieven om toe te werken naar rookvrije omgevingen, die vooralsnog niet bij wet zijn geregeld [4]. In het voorjaar van 2018 kwamen vertegenwoordigers van het Erasmus MC, de Hogeschool Rotterdam en het Erasmiaans Gymnasium voor het eerst bij elkaar om te praten over een gezamenlijke rookvrije zone. Zo'n zone past bij de voorbeeldfunctie van een ziekenhuis en onderwijsinstellingen, en kan overlast en negatieve gezondheidseffecten als gevolg van meeroken mogelijk beperken [5]. Daarnaast kan zo'n zone als onderdeel van een breder plan patiënten, bezoekers, studenten en medewerkers ondersteunen bij het stoppen met roken.

De gebouwen van de drie instellingen liggen aan weerszijden van een openbare weg en zijn centraal gelegen in Rotterdam [6]. In samenspraak met de gemeente werd overeenstemming bereikt over het toewerken naar een rookvrije zone die het Erasmus MC, de Hogeschool en het Gymnasium, alsook de tussenliggende weg omvat. Om het rookgedrag binnen de voorgenomen rookvrije zone te kwantificeren voerden wij een veldonderzoek uit. De uitkomsten hebben bijgedragen aan de verdere vormgeving van de rookvrije zone en laten zien welke winst er te behalen is.

\section{Methode}

\section{Onderzoeksopzet}

Het betrof een observationeel veldonderzoek rondom het Erasmus MC (ongeveer 15.000 medewerkers en 3.700 studenten, jaarlijks ongeveer 32.000 opnamen en 512.000 polikliniekbezoeken) [7], de Hogeschool Rotterdam (ongeveer 1.500 medewerkers en 11.000 studenten) en het Erasmiaans Gymnasium (77 medewerkers en 1.100 leerlingen) [8].

\section{Setting en deelnemers}

Op het moment van de meting was het volgens het Erasmus MC-beleid formeel niet toegestaan om op het ziekenhuisterrein te roken, tenzij expliciet anders aangegeven. Op het terrein bevonden zich vijf rookabri's waarin roken wél was toegestaan. Voor de twee ingangen van de Hogeschool bevond zich een groen omlijnde rookvrije zone. Het Gymnasium had op het moment van de meting geen formeel beleid ten aanzien van roken op het terrein rondom de school. Tijdens het onderzoek waren er door de gemeente en de instellingen in de onderzochte zone nog geen concrete maatregelen genomen om het gebied rookvrij te houden.

\section{Dataverzameling}

Van november 2018 tot januari 2019 hebben wij op vijftien locaties rondom het Erasmus MC, onderverdeeld in 74 sublocaties, het aantal rokers geobserveerd. Het observationele veldonderzoek rondom het Erasmus MC duurde in totaal dertig dagen: 22 dagen tijdens werktijden op doordeweekse dagen, vijf dagen in de avond en drie dagen in het weekend. In maart 2019 hebben we gedurende zeven dagen vijf locaties rondom de Hogeschool en het Gymnasium geobserveerd.

Het observationele veldonderzoek is uitgevoerd door één waarnemer (ND). De observaties rondom het Erasmus MC vonden plaats op doordeweekse dagen van 09:00 tot 16:15 uur (vanaf nu 'werktijden' genoemd). Elke locatie werd per observatiedag gedurende 15 minuten geobserveerd. Door het observatieschema te laten verspringen, werd elke locatie elke dag tijdens een ander kwartier geobserveerd. Tussen elke observatie was er 5 minuten om van locatie te wisselen en werd er niet geobserveerd. Zodoende werd elk uur $3 \times 15$ minuten geobserveerd en was er $3 \times 5$ minuten looptijd. Daarnaast hebben we aparte observaties uitgevoerd op doordeweekse dagen van 17:00 tot 21:55 uur en in het weekend van 10:00 tot 14:55 uur, ook van elk 15 minuten per locatie. Rondom de Hogeschool Rotterdam en het Gymnasium werd elke locatie gedurende 40 minuten geobserveerd. Deze observaties vonden plaats onder werktijd van 09:00 tot 16:30 en ook hier was er een verspringend schema met 5 minuten looptijd tussen de locaties. Het gehele observatieschema is weergegeven in tabel 1 tot en met 4 in de supplementaire documenten (electronic supplementary material).

De waarnemer registreerde van elke roker het exacte tijdstip waarop hij/zij rookte, de (sub)categorie waartoe de roker behoorde (fig. 1), de locatie, of de roker gebruikmaakte van een rookabri dan wel rookte buiten de rookvrije zone bij de Hogeschool, en of 
Figuur 1 Categorieën en subcategorieën rokers. De rood omlijnde subcategorieën werden alleen gebruikt bij het veldonderzoek rondom de Hogeschool en het Gymnasium



de roker zichtbaar verzocht werd om elders te roken wanneer het roken gebeurde op een plek waar dat niet was toegestaan. Ten slotte werden voor elke observatie de weersomstandigheden van dat moment geregistreerd. Rokers werden gecategoriseerd op basis van specifieke kenmerken zoals vermeld in fig. 1 . Indien rokers geen van deze kenmerken hadden of bij twijfel is de roker gecategoriseerd als 'overig'.

\section{Data-analyse}

Beschrijvende analyses werden uitgevoerd met SPSS. Hierbij zijn de verdelingen van categorische variabelen gepresenteerd als aantallen en percentages. Numerieke variabelen zijn gepresenteerd als mediaan met range.

Conform het verspringende observatieschema werd gedurende werktijden op het Erasmus MCterrein geobserveerd gedurende drie kwartier per uur (de overige 15 minuten was looptijd tussen de locaties). Op het terrein rondom de Hogeschool en het Gymnasium werd gedurende 40 minuten per 45 minuten geobserveerd (de overige 5 minuten was looptijd tussen de locaties). Rekening houdend met het percentage niet-geobserveerde tijd werd het totaal aantal rokers per dag gedurende werktijden als volgt geëxtrapoleerd:

\section{Geschat aantal rokers $=$}

((aantal minuten per observatie + geobserveerd $\times \frac{\text { aantal minuten tussen } 2 \text { observaties) }}{\text { aantal minuten per observatie) }}$

Dit was niet mogelijk voor de avond- en weekendobservaties, omdat hier niet op elke locatie elk kwartier geobserveerd was. 

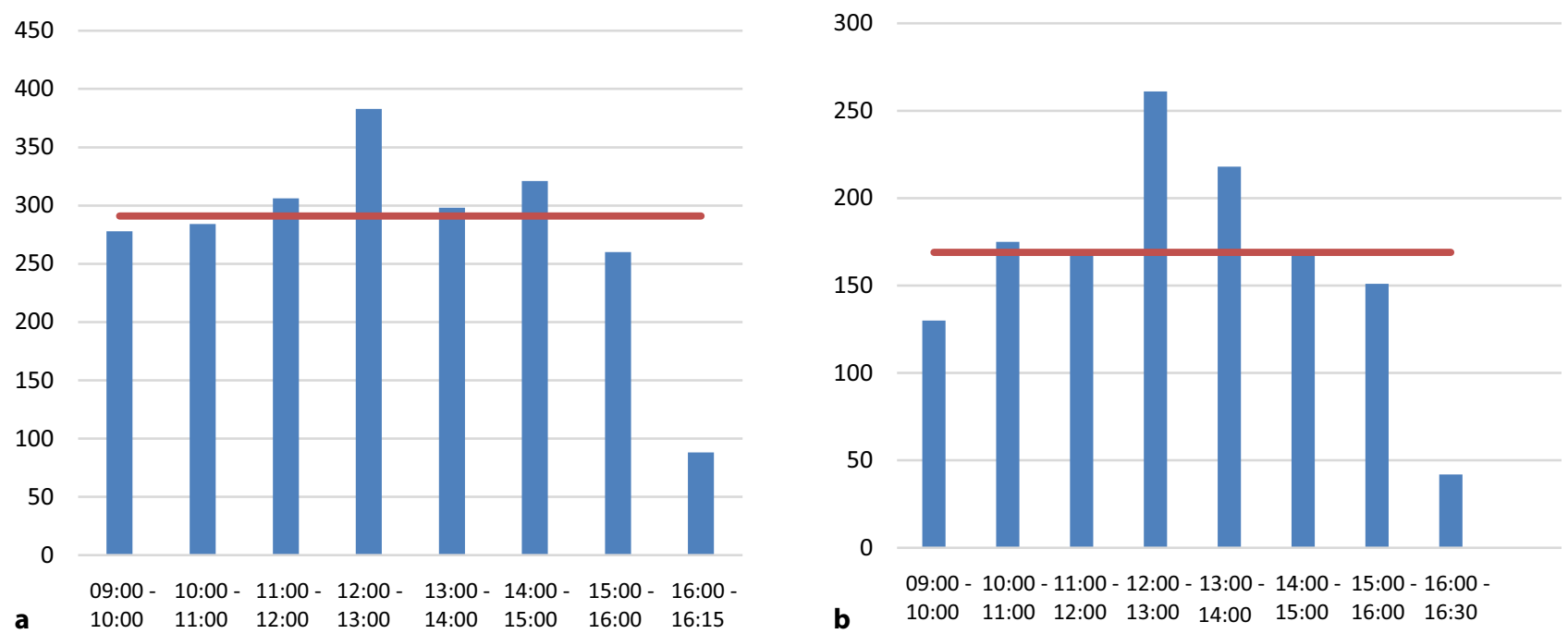

Figuur 2 a Geschat aantal rokers per uur op Erasmus MC-terrein - doordeweekse dagen, werktijden. b Geschat aantal rokers per uur op terrein rondom de Hogeschool en het Gymnasium - doordeweekse dagen, werktijden

\section{Resultaten}

\section{Aantal rokers}

In totaal werden er op alle Erasmus MC-locaties bij elkaar 2.218 rokers geteld. Rekening houdend met de momenten waarop niet werd geobserveerd, betekent dit dat er dagelijks gedurende werktijden naar schatting 2.957 rokers op het Erasmus MC-terrein waren. De mediaan van het geschatte aantal rokers per uur, tijdens werktijden op doordeweekse dagen, was 288 (range 393). Hierbij zijn de meeste rokers tussen 12:00 en 13:00 uur geobserveerd ( $n=511$; range 113) (fig. 2a). De gemiddelde temperatuur gedurende de observaties, tijdens werktijden, rondom het ziekenhuis en de onderwijsinstellingen was $6,2^{\circ} \mathrm{C}$. Bovendien is er op 14 van de 29 dagen tijdens werktijden gedurende een groot deel van de dag neerslag gevallen. Tijdens de observatieperiode was de weersvariatie te beperkt om een duidelijke relatie met het aantal rokers aan te kunnen tonen.

Rondom de Hogeschool en het Gymnasium telden we in totaal 1.315 rokers, overeenkomend met naar schatting 1.479 rokers per doordeweekse dag tijdens werktijden (mediaan per uur 190; range 246; fig. 2b). Ook hier zijn de meeste rokers geobserveerd tussen 12:00 en 13:00 uur ( $n=294$; range 48 ).

\section{Aantal rokers per locatie}

Het geschatte aantal rokers per sublocatie is weergegeven in fig. 3. Het grootste aantal rokers stond nabij de hoofdingang van het Erasmus $\mathrm{MC}$ en in de parkeergarage van het Erasmus MC, respectievelijk 948 en 401 rokers per dag gedurende werktijden. Rondom de Hogeschool en het Gymnasium stonden de meeste rokers voor de feitelijke en de formele hoofdingang van de Hogeschool, respectievelijk 614 en 320 rokers per dag gedurende werktijden.

\section{Categorie en subcategorie van rokers}

Van de rokers rondom het Erasmus MC is $40 \%$ gecategoriseerd als medewerker, $4 \%$ als patiënt en $56 \%$ als overig (fig. 4). Van het totale aantal medewerkers op het Erasmus MC-terrein is $76 \%$ gecategoriseerd als interne medewerker en $24 \%$ als externe medewerker. Van de interne medewerkers was $18 \%$ herkenbaar als zorgverlener.

Van de rokers rondom de Hogeschool en het Gymnasium werd $69 \%$ gecategoriseerd als student, $12 \%$ als medewerker en $19 \%$ als overig. Van de medewerkers is $89 \%$ gecategoriseerd als medewerker Hogeschool, $4 \%$ als medewerker Gymnasium, $4 \%$ als externe medewerker, $1 \%$ als zorgverlener Erasmus MC en $3 \%$ als overig interne medewerker Erasmus MC. Van de studenten is $96 \%$ gecategoriseerd als student Hogeschool en $4 \%$ als student Gymnasium.

De observaties gedurende avonden en weekenden waren beperkter van aard, waardoor een betrouwbare schatting van het aantal rokers voor elke combinatie van tijdstip en locatie niet mogelijk is. Opvallend was wel dat er proportioneel rondom het Erasmus MC meer patiënten in de avond (7\%) en in het weekend $(8 \%)$ rookten, vergeleken met doordeweekse dagen tijdens werktijden $(5 \%)$. Verder waren er proportioneel minder medewerkers die 's avonds $(24 \%)$ rookten dan in het weekend (39\%) en op doordeweekse dagen tijdens werktijden $(40 \%)$. Wel waren er in de categorie medewerkers proportioneel meer zorgverleners die in de avonden (30\%) en in het weekend (39\%) rookten, dan op doordeweekse dagen tijdens werktijden (14\%). 


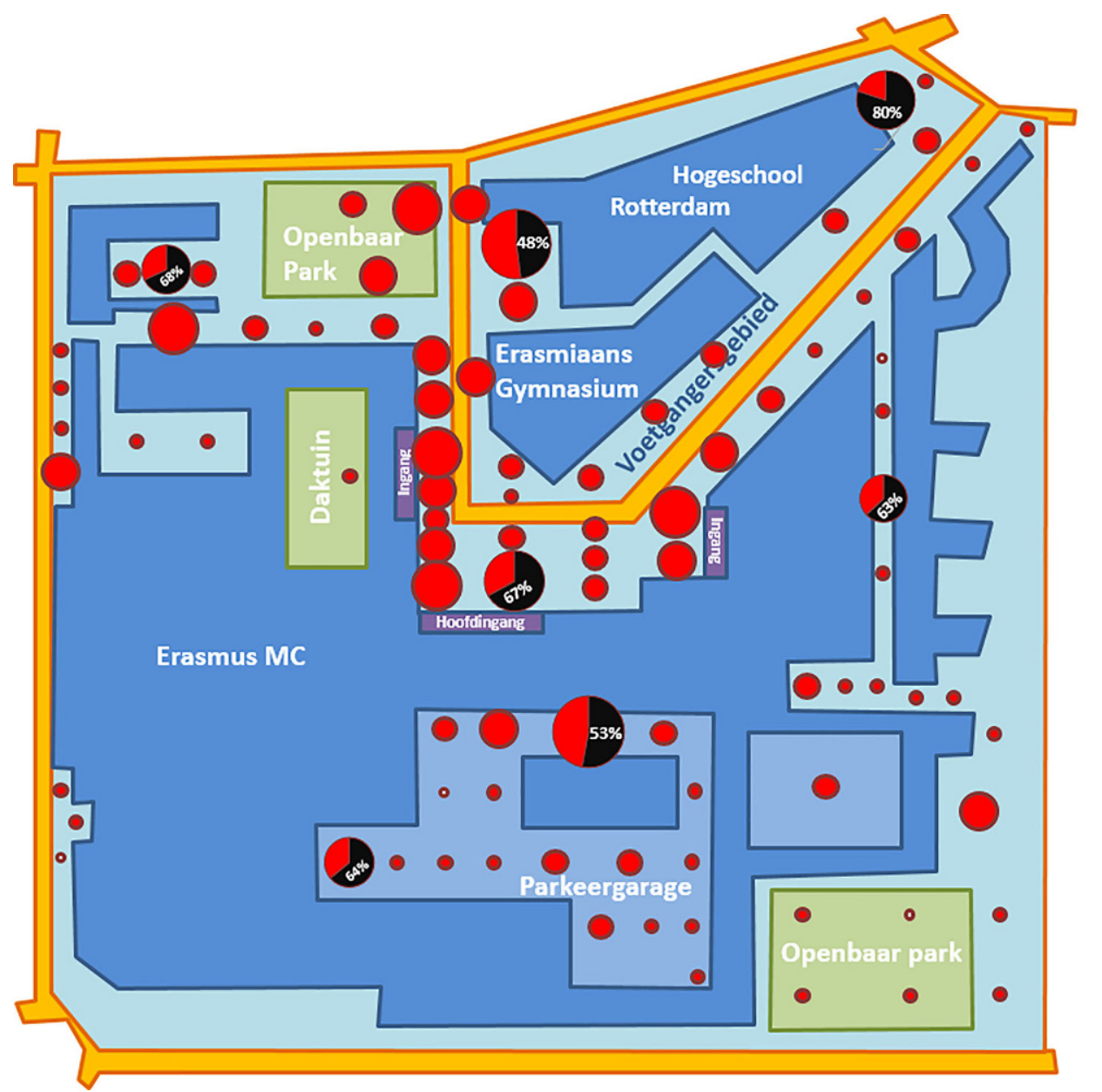

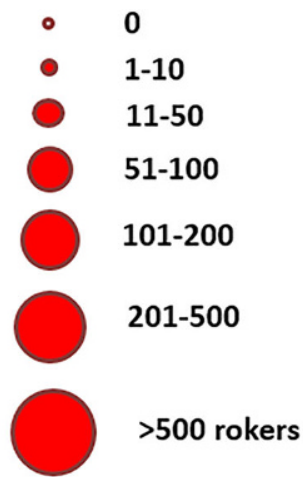

\% Percentage rokers binnen een sublocatie dat gebruik maakte van de rookabri \& Percentage rokers buiten de rookvrije zones

Gebouw Erasmus MC, Hogeschool \& Erasmiaans Weg

Voetgangersgebied

Parkeergarage

Figuur 3 Bubble map met geschat aantal rokers per sublocatie binnen de voorgenomen rookvrije zone (doordeweekse dagen)

\section{Gebruik van rookabri's, het roken binnen de rookvrije zone en handhaving}

Rondom het Erasmus MC maakte $75 \%$ van de rokers geen gebruik van een rookabri. Van hen werd $0,2 \%$ zichtbaar verzocht om elders te roken. Rondom de onderwijsinstellingen rookte $25 \%$ binnen de bestaande rookvrije zone voor een van de ingangen. Van hen werd $5 \%$ zichtbaar verzocht om elders te roken.

\section{Beschouwing}

Dit onderzoek biedt inzicht in de rookpatronen binnen de destijds voorgenomen rookvrije zone rondom het Erasmus MC, de Hogeschool Rotterdam en het Erasmiaans Gymnasium, die per 2 september 2019 formeel rookvrij werd verklaard [9]. Tijdens werktijden overdag waren er naar schatting 4.436 rokers in de voorgenomen rookvrije zone. Opvallend was dat slechts een kwart van de rokers op het Erasmus MCterrein gebruikmaakte van de rookabri's en dat maar enkele rokers zichtbaar werden aangesproken als zij rookten waar dat formeel niet mocht. Het waren de beveiligers van de betreffende instellingen die rokers rondom het ziekenhuis en onderwijsinstellingen op hun rookgedrag aanspraken. Hoewel zij rokers maar zeer beperkt zichtbaar aanspraken, gingen vrijwel alle aangesproken rokers naar een andere locatie om daar te roken. Er werd relatief veel gerookt rondom de ingangen van het ziekenhuis en de Hogeschool, waarbij de blootstelling voor voorbijgangers het grootst is.

Een van de sterke punten van dit onderzoek was de onderzoeksopzet. Voor zover ons bekend, is dit het eerste onderzoek dat het rookgedrag rondom een ziekenhuis en omringende scholen op een systematische wijze heeft vastgelegd. We hebben met onze methode geprobeerd de invloed van variaties in de weersomstandigheden en de dag zelf te minimaliseren door de locaties over meerdere dagen op verschillende tijdstippen te observeren. Uit eerder onderzoek is namelijk gebleken dat het rookgedrag van consumenten temperatuur- en seizoensgebonden is $[10,11]$. Door de inzet van één observator speelt interobserver-variatie geen rol.

Dit onderzoek had ook een aantal beperkingen. Ten eerste hebben we het aantal rokers per dag geschat op basis van observaties gedurende driekwart (Erasmus MC) en $89 \%$ (Hogeschool en Gymnasium) van de tijd, wat leidde tot een beperkte mate van onzekerheid over de precieze aantallen. Daarnaast vonden de ob- 
Figuur 4 a Categorie en subcategorie van geobserveerde rokers - Erasmus MC. b Categorie en subcategorie van geobserveerde rokers-Hogeschool Rotterdam en Erasmiaans Gymnasium
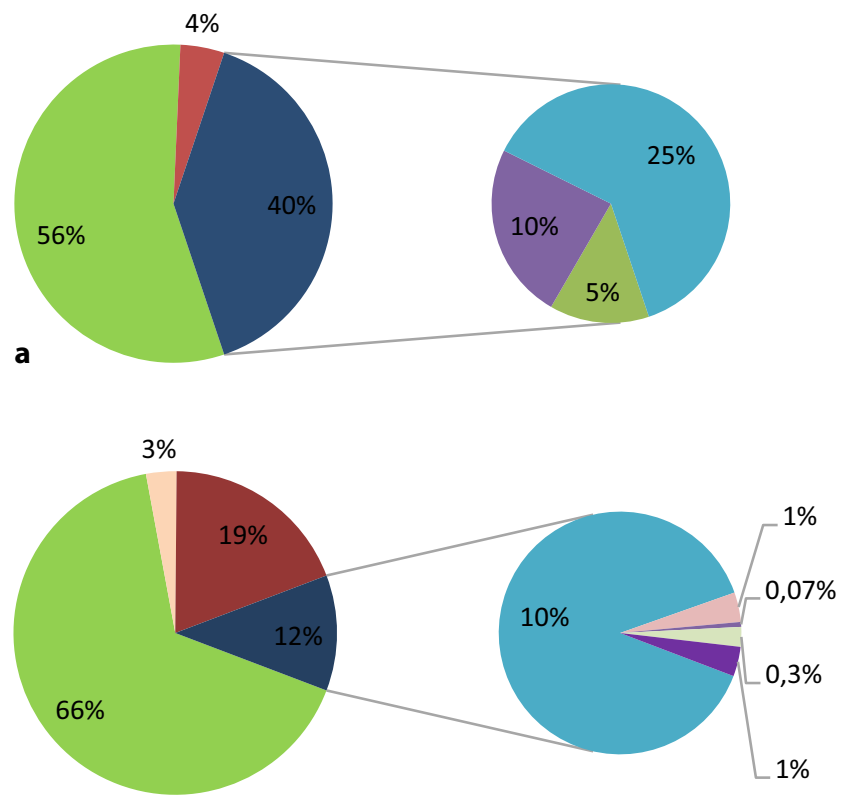

b
Overig

- Patiënten

Zorgverleners

- Externe medewerkers

- Overig interne medewerkers

- Medewerkers

\section{- Student Hogeschool \\ Student Gymnasium \\ - Overig \\ - Medewerkers \\ - Medewerkers Hogeschool \\ - Medewerkers Gymnasium \\ - Zorgverleners Erasmus MC \\ Overig interne medewerkers Erasmus MC \\ - Externe medewerkers}

servaties plaats gedurende de winterperiode, hetgeen een onderschatting zou kunnen geven van het aantal rokers gedurende het jaar, aangezien rokers in slechtere weersomstandigheden minder vaak naar buiten gaan $[10,11]$. Ook was het niet altijd even duidelijk tot welke categorie een roker hoorde, waardoor de categorie 'overig' groot was en het percentage patiënten en medewerkers mogelijk onderschat is. Het observeren of iemand werd verzocht elders te roken, is slechts een momentopname. Hierdoor vormt het aantal rokers dat daadwerkelijk aangesproken werd, mogelijk een onderschatting van het werkelijk aantal. Ook is het aannemelijk dat mensen meerdere malen per dag roken, eventueel op verschillende locaties. We hebben hiermee bij de observatie van de 'rookmomenten' geen rekening gehouden en hebben daardoor sommige rokers waarschijnlijk meer dan eens geteld. De implicatie is dat bij invoering van een rookvrije zone er mogelijk minder rokers hoeven te worden overtuigd om de volledig rookvrije zone te respecteren, dan uit de tellingen in ons onderzoek naar voren kwam.

Dit onderzoek laat zien dat er veel wordt gerookt rondom het ziekenhuis en onderwijsinstellingen, en dat personeel en studenten daar een belangrijk aandeel in hebben. Een opvallende bevinding in ons onderzoek was het grote aantal rokers dat zich niet aan de bestaande regels hield, die voorschreven dat uitsluitend in een rookabri (Erasmus MC) of buiten de rookvrije zone (Hogeschool) gerookt mocht worden. Dit komt overeen met eerder onderzoek uit Australië, waarbij zorgverleners aangaven dat slechts $13 \%$ van hun patiënten en $24 \%$ van de medewerkers altijd/ vaak de rookbeperkingen naleefden [12]. Een veldonderzoek in Australië liet zien dat het vooral personeelsleden en bezoekers zijn die rondom ziekenhui- zen roken, dat zij vaak op minder dan 10 meter van de ingang staan en geregeld de rookbeperkingen niet naleven, hetgeen ook overeenkomt met onze bevindingen [13]. Op een rookvrije universitaire campus elders in Australië zagen onderzoekers dat veel van de rokers student zijn, en dat zij op de hoogte waren van het rookvrije beleid en toch rookten [14].

In het algemeen is de huidige publieke opinie positief over uitbreiding van rookvrije publieke buitenruimten, bijvoorbeeld rondom ziekenhuizen en onderwijsinstellingen [15-18]. Het implementeren van een rookvrij beleid kan op een ziekenhuisterrein zorgen voor een significante vermindering van het fijnstofgehalte in de lucht [5]. Dit impliceert dat een rookvrij beleid niet alleen overlast, maar mogelijk ook negatieve gezondheidsimpact zou kunnen beperken. Onderzoek is nodig om te evalueren in hoeverre rookvrije terreinen rondom ziekenhuizen en onderwijsinstellingen daadwerkelijk bijdragen aan een veranderende beeldvorming en sociale normverandering rondom roken.

Sinds 2 september 2019 is het gebied rondom het Erasmus MC, de Hogeschool en het Gymnasium een rookvrije zone. Dit initiatief wordt ondersteund vanuit de gemeente, die het openbare gebied dat binnen de zone valt ook rookvrij heeft verklaard. Dit onderzoek geeft niet alleen aan hoeveel winst er te behalen is ten aanzien van het beperken van roken in dit gebied, maar dat er tegelijk ook uitdagingen zullen zijn wat betreft de handhaving. Er wordt momenteel onder andere ingezet op adequate informatievoorziening, inclusief bebording en belijning van de zone, en op ontwikkeling van een algemene aanspreekcultuur bij non-compliance. Op gezette tijden lopen betrokken medewerkers rondes om gesprekken aan te gaan 
met mensen die toch binnen de rookvrije zone roken. Hoewel de bewaking hierin een formele rol heeft, bestaat de hoop dat op den duur sociale normveranderingen zullen optreden, zoals eerder na landelijke invoer van rookvrije publieke binnenruimten is gebeurd. Gesteund door de gegevens van dit onderzoek is onder andere besloten om de rookabri's volledig te verwijderen. Het Erasmus MC ondersteunt vanuit haar visie voor een gezonde bevolking het concept van de Rookvrije Generatie en faciliteren van roken op het terrein hoort daar niet bij. Als onderdeel van het bredere kader van het Rookvrij Erasmus MC-concept is verder onder andere een zorgpad voor rokende patiënten ontwikkeld en is een gratis ondersteuningsprogramma gelanceerd voor medewerkers die willen stoppen met roken. Landelijk is de Toolkit Rookvrije Zorg ontwikkeld die instellingen praktische handvatten biedt om volledig rookvrij te worden [19]. Toekomstige evaluaties zijn nodig om de compliance, het aanspreekgedrag en eventuele verdringing van roken naar locaties net buiten de rookvrije zone te monitoren.

\section{Conclusie}

Dagelijks waren er veel rokers in het voorgenomen rookvrije gebied in Rotterdam, waarbij de meesten van hen rookten nabij de ingangen van het Erasmus MC en de Hogeschool. Hierbij was het gebruik van de rookabri's en het aanspreekgedrag minimaal. Een rookvrije zone past bij de voorbeeldfunctie van een ziekenhuis en onderwijsinstellingen, en kan overlast en negatieve gezondheidseffecten als gevolg van meeroken mogelijk beperken. De uitkomsten van dit onderzoek laten zien welke winst er te behalen is bij de implementatie van een volledig rookvrij beleid.

Open Access This article is licensed under a Creative Commons Attribution 4.0 International License, which permits use, sharing, adaptation, distribution and reproduction in any medium or format, as long as you give appropriate credit to the original author(s) and the source, provide a link to the Creative Commons licence, and indicate if changes were made. The images or other third party material in this article are included in the article's Creative Commons licence, unless indicated otherwise in a credit line to the material. If material is not included in the article's Creative Commons licence and your intended use is not permitted by statutory regulation or exceeds the permitted use, you will need to obtain permission directly from the copyright holder. To view a copy of this licence, visit http://creativecommons.org/licenses/by/4.0/.

\section{Literatuur}

1. Mackenbach JP, Damhuis RAM, Been JV. De gezondheidseffectenvan roken: groeivan kennisleidt totsteeds grimmiger beeld. NedTijdschr Geneeskd. 2017;161(2):D869.
2. Rijksinstituut voor Volksgezondheid en Milieu. Sterfte door roken. Beschikbaar via: https://www.volksgezond heidenzorg.info/onderwerp/roken/cijfers-context/ gevolgen\#node-sterfte-door-roken.

3. Ministerie van Volksgezondheid, Welzijn en Sport. Nationaal Preventieakkoord: naar een gezonder Nederland. 2018. www.rijksoverheid.nl. Geraadpleegd op 24 juni 2019.

4. Kanter W de. De rookvrije generatie. Ned Tijdschr Geneeskd. 2016;160:D315.

5. SuredaX, Ballbè M, Martínez C, etal. Impact of tobacco control policies in hospitals: evaluation of a national smokefree campus ban in Spain. Prev Med Rep. 2014;1:56-61.

6. Gemeente Rotterdam. Rotterdam krijgt rookvrije zone. Persberichten Rotterdam. 2019. https://www. persberichtenrotterdam.nl/bericht/2878/Rotterdamkrijgt-rookvrije-zone/. Geraadpleegd op 26 augustus 2019.

7. Erasmus MC. Jaarverslag en jaarrekening. 2018. https:// www.erasmusmc.nl/nl-nl/patientenzorg/jaarverslag-enjaarrekening. Geraadpleegd op 24 juni 2019.

8. VO-Raad. Scholen op de kaart. 2019. https:// www.scholenopdekaart.nl/Middelbare-scholen/2643/ Erasmiaans-Gymnasium/categorie/Algemeen. Geraadpleegd op 24 juni 2019.

9. Gemeente Rotterdam. Rookvrije zone rondom Erasmus MC. 2019. https://www.rotterdam.nl/nieuws/rookvrijezone/. Geraadpleegd op 13 september 2019.

10. Chandra S, Chaloupka FJ. Seasonality in cigarette sales: patterns and implications for tobacco control. Tob Control. 2003;12(1):105-7.

11. Momperousse D, Delnevo CD, Lewis MJ. Exploring the seasonality of cigarette-smoking behaviour. Tob Control. 2007;16(1):69-70.

12. McCrabb S, Baker AL, Attia J, et al. Hospital smoke-free policy: compliance, enforcement, and practices. A staff survey in two large public hospitals in Australia. Int J Environ Res Public Health. 2017;14(11):1358.

13. Nagle AL, Schofield MJ, Redman S. Smoking on hospital grounds and the impact of outdoor smoke-free zones. Tob Control. 1996;5(3):199-204.

14. Jancey J, Bowser N, Burns S, et al. No smoking here: examining reasons for noncompliance with a smoke-free policy in a large university. Nicotine Tob Res. 2014;16(7):976-83.

15. Koh HK, Alpert HR, Judge CM, et al. Understanding worldwide youth attitudes towards smoke-free policies: an analysis of the Global Youth Tobacco Survey. Tob Control. 2011;20(3):219-25.

16. Shopik NA, Schultz ASH, Nykiforuk CIJ, et al. Impact of smoke-free hospital grounds policies: patient experiences and perceptions. Health Policy. 2012;108(1):93-9.

17. Martin K, Dono J, Sharplin G, et al. Staff and patient perspectives of a smoke-free health services policy in South Australia: a state-wide implementation. Health Policy. 2017;121(8):895-902.

18. Kankerbestrijding KWF. Driekwart Nederlanders pleit voor actief rookvrij beleid. 2019. https://www.kwf.nl/ pers/driekwart-nederlanders-pleit-voor-actief-rookvrijbeleid. Geraadpleegd op 3 december 2019.

19. Trimbos-instituut. Rookvrije Zorg Toolkit. 2019. https:// www.rookvrijezorg.com/toolkit/. Geraadpleegd op 3 december 2019 . 